\title{
Molecular signatures from kerogens preserved in 3.42 Ga microbial mats (Buck Reef Chert, Barberton Greenstone Belt, South Africa)
}

\author{
MANUEL REINHARDT ${ }^{1,2, *}$, VOLKER THIEL ${ }^{2}$, HENRIK
} DRAKE $^{1}$, WALTER GOETZ ${ }^{3}$, AND JOACHIM REITNER ${ }^{2}$

${ }^{1}$ Linnaeus University, Kalmar, Sweden

${ }^{2}$ University of Göttingen, Göttingen, Germany

${ }^{3}$ Max Planck Inst. Solar Sys. Res., Göttingen, Germany

(*correspondence: mreinha@gwdg.de)

The 3.42 Ga Buck Reef Chert (Barberton Greenstone Belt, South Africa) provides a rare sequence of exceptionally well preserved silicified microbial mats, containing abundant kerogen ${ }^{[1]}$. We investigated this macromolecular organic material (cherts from drill cores, Barberton Drilling Project Peering into the Cradle of Life) on structural (microscopy, FTIR/ATR, Raman), and molecular level (HyPy followed by GC-MS). Kerogen is solely associated with microbial mat structures and not entrapped in any post-depositional veins or microfractures. Raman confirmed the regional peak metamorphic temperatures (greenschist facies) and therefore supports the syngeneity of the kerogens. While FTIR/ATR mostly indicated an overall graphitic structure, GC-MS after HyPy treatment revealed robust above-blank-concentrations of aliphatic and aromatic hydrocarbons. In the two-step heating approach used $\left(330{ }^{\circ} \mathrm{C} / 520^{\circ} \mathrm{C}\right)$, these compounds exclusively occurred in the high-T HyPy runs, thus pointing to cracking of covalent bonds in the kerogens. Detected $n$ alkane homologues $\left(\mathrm{C}_{12}-\mathrm{C}_{26}\right)$ showed a noticeable decrease in abundance after $n-\mathrm{C}_{16}$ and $n-\mathrm{C}_{18}$. Further, isomeric mixtures of monomethyl alkanes $\left(\mathrm{C}_{12}-\mathrm{C}_{21}\right)$ and low amounts of PAHs were found. Preferences in chain-length of $n$-alkanes are not known from abiotic organic matter (FTT and extraterrestrial). The idea that these distributions instead may represent a syngenetic biological signal, is supported by (i) the thermal stability of $n$-alkanes ${ }^{[2]}$ (ii) the careful state-ofthe-art kerogen isolation, including extensive extraction, swelling, and blanks, (iii) the two-step HyPy approach used, (iv) similar findings in hydropyrolysates from $>3.4$ Ga chert kerogens of the Pilbara Craton ${ }^{[3],[4]}$, and (v) the occurrence of kerogen exclusively in microbial mat structures. To further decode the origin of these molecular fingerprints, compound specific stable carbon isotopes will be analyzed.

[1] Homann (2019), Earth Sci. Rev. 196, e102888. [2] Price (1993), Geochim. Cosmichim. Acta 57, 3261-3280. [3] Marshall et al. (2007), Precambrian Res. 155, 1-23. [4] Duda et al. (2018), Biogeosciences 15, 1535-1548. 